\title{
Correspondence: Prostatic sarcoma after treatment for rectal
}

\section{cancer}

\author{
Noel J Aherne and Charles M Gillham*
}

\author{
Address: Department of Radiation Oncology, St. Luke's Hospital, Dublin 6, Ireland \\ Email: Noel J Aherne - noelaherne@eircom.net; Charles M Gillham* - cmgillham@yahoo.com \\ * Corresponding author
}

Published: 17 February 2008

World Journal of Surgical Oncology 2008, 6:20 doi:10.1186/1477-7819-6-20

This article is available from: http://www.wjso.com/content/6/1/20

(C) 2008 Aherne and Gillham; licensee BioMed Central Ltd.

This is an Open Access article distributed under the terms of the Creative Commons Attribution License (http://creativecommons.org/licenses/by/2.0), which permits unrestricted use, distribution, and reproduction in any medium, provided the original work is properly cited.
Received: 4 September 2007

Accepted: 17 February 2008
Dear Sirs,

The authors Abbas SM, and Hill AG [1] outline their experience of a case of prostatic sarcoma occurring four years post neoadjuvant radiation therapy for primary mid rectal adenocarcinoma. They correctly state that as this second malignancy occurred within the radiation field it meets the criteria for a radiation - induced second malignancy. However, it has been noted that while there is no established dose response relationship for sarcoma that they are generally felt to occur within the high dose region. A dose of 4500 cGy seems unlikely to lead to sarcoma formation within such a short time frame.

While post radiation sarcomas have commonly been described in the pelvis they more commonly follow high dose 3 Dimensional Conformal Radiation therapy (3DCRT) with or without intracavitary brachytherapy (doses > 7000 cGy) in gynecological cancers, or in combination with interstitial seed brachytherapy (doses $>1000$ cGy) in prostatic malignancy. In contrast, primary prostatic sarcoma is a well recognized clinical entity with over 50 cases recorded in the literature [2-4].

While the author's assertion that this is a radiation induced second malignancy is supported by the temporal association, radiobiologically it is not. However, this case is a salient reminder of the significant risks associated with all forms of cancer therapy.

\section{Competing interests}

The author(s) declare that they have no competing interests.

\section{Authors' contributions}

NJA: Conception and design, editing of manuscript.

CMG: preparation of draft manuscript.

All authors read and approved final manuscript.

\section{References}

I. Abbas SM, Hill AG: Prostatic sarcoma after treatment of rectal cancer. World Journal of Surgical Oncology 2007, 5:82.

2. Sexton WJ, Lance RE, Reyes AO, Pisters PW, Tu S, Pisters L: Adult Prostate Sarcoma: The M.D Anderson cancer centre experience. J Urol 200I, 166:52I-525.

3. Cheville JC, Dundore PA, Nascimento AG, Meneses M, Kleer E, Farrow GM, Bostwick DG: Leiomyosarcoma of prostate: Report of 23 cases. Cancer 1995, 76:1422-1477.

4. Mansouri H, Kanouni L, Kebdani T, Hassouni K, Sifat H, Gueddari BE: Primary prostatic leiomyosarcoma. J Urol 200I, 165:1676. 